\title{
Constituição de sentidos subjetivos do processo ensino e aprendizagem no Ensino Superior
}

\author{
Silvia Simão de Matos \\ Universidade da Região de Joinville - Joinville - SC \\ Márcia de Souza Hobold \\ Universidade da Região de Joinville - Joinville - SC
}

\begin{abstract}
Resumo
Tendo em vista a importância de investigações sobre o trabalho docente no ensino superior no âmbito da psicologia educacional, a presente pesquisa teve como objetivo conhecer a relação do trabalho docente com a constituição de sentidos subjetivos no processo de ensino e aprendizagem neste nível de ensino. Para a coleta de dados foram utilizados: grupos de discussão, entrevistas, complemento de frases etc., com estudantes e professores de uma universidade comunitária de Santa Catarina. A análise dos dados foi fundamentada por Jusevicius (2006), González Rey (2005; 2007), Stangherlim (2007) e Marinho-Araújo (2009). Os resultados revelaram que o trabalho docente tem forte relação com a constituição de sentidos subjetivos no ensino superior, envolvendo tanto o aspecto acadêmico quanto os aspectos profissionais e comportamentais; é forte a influência dialética entre professores e estudantes nesse processo, sendo que o contexto sócio-histórico-cultural é constituído e constituinte de sentidos nos espaços educativos do ensino superior.
\end{abstract}

Palavras-chave: Trabalho docente; psicologia educacional; ensino superior.

\section{Establishment of subjective sense of teaching and learning process in} Higher Education

\begin{abstract}
Given the importance of research into the teaching profession in higher education within the educational psychology, this study aimed to assess the relationship of teaching to the constitution of subjective senses in the process of teaching and learning in higher education. For data collection were used: focus groups, interviews, sentences complement etc., with students and teachers at a community college of Santa Catarina. Data analysis was substantiated by Jusevicius (2006), González Rey (2005; 2007), Stangherlim (2007) Marine-Araujo (2009). The results revealed that the teaching profession is strongly related to the constitution of subjective senses in higher education, involving both the academic aspect, as professionals and behavioral aspects; and that there is a strong influence dialectic between teachers and students in this process, and the sociohistorical-cultural context is constituted and constituent of meanings in educational spaces of higher education.
\end{abstract}

Keywords: Teaching work; educational psychology; higher education.

\section{Constitución de sentidos subjetivos del proceso enseñanza y aprendizaje en la Enseñanza Superior}

\section{Resumen}

Teniendo en vista la importancia de investigaciones sobre la labor docente en la enseñanza superior en el ámbito de la psicología educacional, la presente investigación tuvo como objetivo conocer la relación de la labor docente con la constitución de sentidos subjetivos en el proceso de enseñanza y aprendizaje en este nivel de enseñanza. Para la recolecta de datos se utilizó: grupos de discusión, entrevistas, complemento de frases etc., con estudiantes y profesores de una universidad comunitaria de Santa Catarina. El análisis de los datos fue fundamentado por Jusevicius (2006), González Rey (2005; 2007), Stangherlim (2007) y Marinho-Araújo (2009). Los resultados revelaron que la labor docente tiene fuerte relación con la constitución de sentidos subjetivos en la enseñanza superior, involucrando tanto es aspecto académico como los aspectos profesionales y comportamentales; es fuerte la influencia dialéctica entre profesores y estudiantes en ese proceso, siendo que el contexto sociohistórico-cultural es constituido y constituyente de sentidos en los espacios educativos de la enseñanza superior.

Palabras clave: Labor docente; psicología educacional; enseñanza superior. 


\section{Introdução}

O estudo aqui apresentado é o resultado da pesquisa qualitativa realizada em um curso de graduação de uma universidade comunitária de Santa Catarina, tanto com professores quanto com alunos. O objetivo foi conhecer a relação do trabalho docente com a constituição de sentidos subjetivos no processo de ensino e aprendizagem no Ensino Superior. Para isso, foi utilizado como referencial teórico a abordagem sócio-histórica, com destaque para González Rey que fundamenta o estudo sobre sentidos subjetivos.

Estudar, pesquisar e conhecer qual a relação do trabalho docente para a constituição dos sentidos subjetivos no Ensino Superior demandou um olhar para os sujeitos de pesquisa de forma processual, implicou na utilização de instrumentos diferenciados de coleta de dados e de uma análise permanente das informações, construindo a compreensão dos fatos no decorrer da investigação. Representou, ao mesmo tempo, a articulação de saberes apreendidos no campo da psicologia educacional. Nesse percurso, os sentidos subjetivos foram sendo descortinados, sendo conhecidos e compreendidos dentro do espaço de ensino-aprendizagem nas e pelas experiências educativas.

Serpa e Santos (2001, p. 29) fazem referência a Von Buettner (1997), que sugere "o desenvolvimento de práticas de atuação mais ousadas", referindo-se às possibilidades de atuação do psicólogo no ensino superior. As mesmas autoras enfatizam que "o ensino superior constitui um campo de trabalho privilegiado para o psicólogo escolar" (Serpa, \& Santos, 2001, p. 29).

Nesse espaço de aprendizagem e de encontro, os aspectos subjetivos de cada um influenciam e interferem no processo de constituição identitária, seja de forma individual, profissional ou com relação à constituição do próprio grupo. Tacca e González Rey (2008, p. 143), referindo-se aos sujeitos do processo de ensino-aprendizagem, ressaltam que "[...] serão, sem dúvida, muitas as experiências que o marcarão e que constituirão a sua subjetividade".

Em estudos realizados por Bariani, Buin, Barroz e Escher (2004, p. 20) ficou constatado que o "[...] intercâmbio de influências comportamentais entre professor e aluno tem uma importância particular". Os mesmos autores acrescentam que em função da forma como ocorre a "interação professor-aluno, a adaptação e a aprendizagem do estudante podem ser mais ou menos facilitadas e mais orientadas para uma ou outra direção" (Bariani, \& cols., 2004, p. 20).

O estudo da constituição dos sentidos subjetivos está diretamente ligado ao conhecimento das vivências de estudantes e professores. São as experiências de ambos que constituem diferentes elementos de sentido e de significado que irão se traduzir na própria subjetividade. Os sentidos subjetivos "não são jogos de linguagem" (González Rey, 2005b, p. 129), mas são constituídos ao longo da vida de cada indivíduo, por meio das experiências, das motivações, das emoções e dos sentimentos vivenciados.

O processo de constituição de sentidos subjetivos ocorre pela organização das configurações de sentido constituídas nas experiências do indivíduo ao longo de sua vida. Fazem parte desse processo a subjetividade já existente, o repertório, as emoções, o pensamento e a linguagem. A subjetividade atua como resultado de muitos sentidos constituídos no curso das vivências de cada um; o repertório enquanto ocorrem os desdobramentos simbólicos das experiências; as emoções dando sentido subjetivo aos conteúdos; o pensamento organizando as informações; e a linguagem como expressão dos sentidos subjetivos constituídos e constituintes da subjetividade de cada sujeito. Nesse processo estaria, então, caracterizada a relação dialética entre o sujeito e o contexto, e entre os sujeitos das relações.

Jusevicius (2006, p. 30), referenciando González Rey (1995) enfatiza que para ele "[...] o aprendizado é concebido como um processo humano complexo que se expressa como configuração subjetiva e processo interativo". Subjetivo, pois cada integrante será motivado e dará sentido às suas vivências de forma particular, única e ao longo de sua história. Interativo, na medida em que aprender tem relação direta com a troca, com a partilha, com a convivência, com o conhecimento, com a permanente construção, desconstrução e reconstrução de significados e de sentidos.

De acordo com González Rey (2007):

A nossa definição de categoria sentido subjetivo orientase a apresentar o sentido como momento constituinte e constituído da subjetividade, como aspecto definidor desta, enquanto é capaz de integrar formas diferentes de registro (social, biológico, ecológico, semiótico etc.) numa organização subjetiva que se define pela articulação complexa de emoções, processos simbólicos e significados, que toma formas variáveis e que é suscetível de aparecer em cada momento com uma determinada forma de organização dominante (p. 170).

Subjetividade que está inserida no processo educativo e é resultante dos sentidos subjetivos dados por cada um a cada etapa, a cada vivência e interfere na constituição de outros sentidos no decorrer da vida de cada um. Sentidos subjetivos que diferem de significações, pois dar significado ao que se aprende seria somente dar sentido a um conteúdo. Entretanto, como agentes humanos que interagem no processo, "a categoria de sentido é inseparável de uma carga emocional que chamo de sentido subjetivo" (González Rey, 2005b, p. 101).

González Rey (2005b) reforça o exposto acima afirmando que "[...] o sentido está associado a uma produção estável de emocionalidade que não se reduz aos significados que se configuram nele" (p. 102). O autor acrescenta, ainda, que "o sujeito é sujeito de pensamento [...] de um pensamento entendido como processo de sentido" (p. 235), devendo esse processo ser compreendido como atuante "por meio de situações e conteúdos que implicam a emoção do sujeito" (González Rey, 2005, p. 235). Pode-se complementar dizendo que "a linguagem e o pensamento se expressam a partir do estado emocional de quem fala e pensa" (González Rey, 2005, p. 236) e essas estariam ligadas diretamente à constituição de sentidos. 
Stangherlim (2007) salienta que:

Ao analisar sentidos subjetivos, observam-se e registram-se modos de falar, pensar e agir de um sujeito produtor de uma emoção comprometida com o processo de construção de sentidos - advindos das mais diversas procedências - que se fazem presentes no espaço social de investigação (p. 27).

Esta afirmação de Stangherlim é reforçada por González Rey (citado por Tacca, \& González Rey, 2008) quando ele diz que o sentido subjetivo "representa um sistema simbólico-emocional em constante desenvolvimento" ( $p$. 145). Ou seja, a constituição de sentidos é feita de forma processual, permanente, mutável e que carrega em si a carga emocional atribuída pelo sujeito em cada situação.

Para conhecer os sentidos subjetivos envolvidos no processo de ensino-aprendizagem, especialmente no que tange à relação do trabalho docente com a constituição de sentidos, é necessário investir esforços na busca dos múltiplos motivos que envolvem o ato de estudar, de aprender e de ensinar. Somando-se a isso, deve-se atentar para as relações interpessoais inerentes ao processo educativo.

\section{Método}

Os procedimentos utilizados na presente pesquisa foram inspirados na metodologia utilizada na tese de doutoramento de Vanessa Cristina Cabrelon Jusevicius (2006), orientada e fundamentada teoricamente nos princípios da epistemologia qualitativa de González Rey (2005a).

Jusevicius (2006) salienta que na epistemologia qualitativa "[...] há o reconhecimento de que o pesquisador faz parte do processo e nele interfere" (p. 47). Esse reconhecimento é importantíssimo quando, como no caso desta pesquisa, busca-se conhecer a relação da constituição dos sentidos subjetivos com os aspectos do trabalho docente. Foi por meio da participação ativa do pesquisador que significados foram compreendidos e sentidos foram conhecidos parcialmente, pois, como afirma Jusevicius (2006) "[...] não existe uma relação linear entre a representação explícita da palavra e os sentidos subjetivos" (p. 48) e, nessa condição, "[...] há a necessidade de acessar estes elementos por diferentes formas" (Jusevicius, 2006, p. 48).

A pesquisa foi realizada com professores e estudantes do ensino superior de uma Universidade Comunitária de Santa Catarina, com a participação de 25 estudantes da quarta série, última série do curso que, neste caso, apresenta como características a formação de bacharelado, na forma seriada e anual. Esta série foi escolhida tendo em vista que o processo relacional entre estudantes e professores vinha se desenvolvendo desde a primeira série do curso. Este critério foi considerado porque se acredita que o vínculo prolongado contribui para o estudo da constituição dos sentidos subjetivos no processo de ensino e aprendizagem no Ensino Superior.
Nesta última série do curso, quatro disciplinas são ministradas, cada uma por um professor. Neste caso, dos quatro professores, um não pode participar da pesquisa devido ao seu afastamento temporário da disciplina. Quanto ao perfil síntese dos três professores participantes da pesquisa, pode-se destacar que a formação acadêmica foi realizada em cursos de bacharelado, específica na área de atuação do curso, o contrato de trabalho com a Universidade é de professor horista, são do sexo feminino, e quanto à idade duas têm aproximadamente 25 anos e outra 38 .

A escolha dos instrumentos foi baseada em Jusevicius (2006), que utilizou cinco diferentes formas de estímulo à comunicação e à participação de professores e estudantes. Segundo González Rey (2005a) os instrumentos são "simplesmente indutores de informação que não definem o sentido final dela" (p. 79). É preciso que sejam utilizadas diferentes formas para ter acesso aos sentidos subjetivos dados pelos sujeitos da pesquisa de forma que seja possível a sua investigação sob vários ângulos, em diferentes momentos.

O desenvolvimento da coleta de dados foi realizado de forma individual e em grupo, por meio do diário de campo, de conversas informais, do complemento de frases, de grupo de discussão e de entrevistas com os professores. O diário de campo permitiu "[...] fazer o registro das observações e impressões em momento real" (Jusevicius, 2006, p. 61), contribuindo de forma significativa para o registro da participação do pesquisador nas salas de aula e laboratórios do curso. As conversas informais, como um instrumento de coleta de informações, ocorreram em ambientes como a cantina, a sala dos professores, os laboratórios e os corredores da universidade, quando o pesquisador participou de eventos em ambientes distintos e não formais de educação.

A entrevista com professores foi realizada de forma individual, de acordo com a disponibilidade dos participantes. Foram feitas três entrevistas com professores da quarta série do curso, sendo que em um caso foi necessária a realização de dois encontros para complementação das informações. Cabe salientar que a utilização de entrevista nesta pesquisa, de cunho qualitativo, "[...] tem sempre o propósito de converter-se em diálogo, em cujo curso as informações aparecem na complexa trama em que o sujeito as experimenta em seu mundo real" (González Rey, 2005a, p. 89). Nesse caso, foram utilizadas perguntas abertas que permitiram a liberdade dos entrevistados nas respostas.

Para o grupo de discussão foram convidados os 25 estudantes que compunham a série pesquisada, sendo que apenas 10 mostraram interesse em participar. Com os estudantes que se voluntariam a participar do grupo de discussão foi agendado horário e local, respeitando a disponibilidade destes e teve duração de aproximadamente 70 minutos. Para González Rey, no grupo de discussão o sujeito "[...] constrói de forma progressiva sua experiência por meio do diálogo que estabelece com o pesquisador ou com outros sujeitos" (2005a, p. 88).

Já o complemento de frases é apresentado por González Rey (2005a) como um indutor curto para a coleta de 
dados, foi respondido anonimamente pelos 25 estudantes e trouxe informações complementares para a compreensão dos sentidos subjetivos que permeiam a relação entre professores e estudantes e o ambiente educacional no Ensino Superior.

A análise dos dados organizou as informações em categorias que, para Lüdke e André (1986), se constituem após exaustivas leituras das informações coletadas, como uma forma de impregnação dos dados, construindo categorias descritivas e articulando-as ao referencial teórico da pesquisa. Vale destacar que a categorização não esgota a análise, mas cumpre o papel de nortear o olhar do pesquisador que precisa inferir explicações e interpretações aos dados que vão além das informações codificadas.

Vale salientar que a referida pesquisa seguiu as orientações da Resolução do Conselho Nacional de Saúde [CNS] 196/96 (Brasil, 1996),vigente na época da pesquisa, sendo aprovada pelo Comitê de Ética com Seres Humanos;os participantes assinaram o Termo de Consentimento Livre Esclarecido - TCLE.

\section{Apresentação e discussão dos resultados}

Diante da diversidade dos dados, optou-se por apresentá-los em três categorias descritivas: (1) a docência no Ensino Superior; (2) o estudante no Ensino Superior; (3) e o trabalho docente e a constituição de sentidos subjetivos. Essa estrutura cumpre a função de organizar as informações visando facilitar a apresentação e discussão dos dados. Cabe salientar, também, que os nomes aqui utilizados são fictícios, visando preservar a identidade dos participantes desta pesquisa.

\section{A docência no ensino superior}

Moreira (citado por Santos, 2001) salienta que o processo de ensino-aprendizagem é constituído pelo professor, pelo aluno, pelo conteúdo e pelas variáveis ambientais (características da escola). Essas características no Ensino Superior, atualmente, envolvem muito mais do que uma sala de aula composta por professores e estudantes. No ambiente universitário também estão presentes equipamentos como notebook, que amplia e dissemina o convívio com redes sociais e sistemas de busca na internet, dentre muitos outros elementos. Tudo isso compete com o professor e faz com que suas estratégias/metodologias de ensino necessitem de atualização permanente e de muito dinamismo.

Essa situação é corroborada pela professora Cátia, uma das docentes participante da pesquisa, quando afirma que: "o professor também precisa estar conectado, estar 'fuçando' até além do que os alunos estão vendo para que quando eles coloquem aquilo em sala de aula você já está ligado e já viu outra coisa daquilo".

Broilo, Fagundes, Gomes, Jardim e Braccini (2010, p. 84) salientam que "[...] a construção da docência univer- sitária move-se para além do desejo ingênuo, altruísta e idealista". A realidade da atuação docente é permeada por grandes desafios, não só metodológicos e teóricos, mas de "[...] aumento da carga de trabalho, a produtividade quantitativa, os baixos salários, entre outros" (Broilo, \& cols., p. 84).

Os mesmos autores destacam, ainda, que a constituição da profissionalidade docente no ensino superior tem que ser discutida. "O exercício da docência dá-se, fundamentalmente, a partir de elementos que o professor traz de sua trajetória como aluno" (Broilo, \& cols., p. 83). Essa trajetória é constitutiva de sentidos subjetivos que estarão presentes no ambiente educativo e influenciarão no processo de formação dos estudantes de graduação, como podemos observar em outro depoimento da professora Cátia: "[...] a maior dificuldade no trabalho de ser professor é o tempo; a gente tem que ler muita coisa, é exaustivo porque você quer conhecer mais e não dá conta; parece que sempre está faltando alguma coisa".

Essa afirmação está relacionada, também, ao perfil atual do estudante do Ensino Superior, com a dinâmica da informação, a facilidade de acesso e as múltiplas possibilidades de busca da informação. Uma realidade que afeta diretamente a atuação do docente que também precisa cumprir seus horários e as exigências de diferentes atividades, tanto dentro da universidade quanto em suas atividades externas.

$\mathrm{O}$ aspecto mais evidenciado pelos entrevistados em todos os instrumentos utilizados foi a qualidade do relacionamento entre professor e estudante. Sobre essa temática Souza (2009) salienta que "[...] a sala de aula moderna é lugar de encontro, de troca de experiências, de construção e reconstrução do conhecimento" (p. 134) e nesse espaço professores e estudantes interagem, influenciam e são influenciados por essas relações. A mesma autora afirma que as relações "[...] complexificam-se a cada dia, diante das exigências do mercado de trabalho e dos desafios colocados por uma sociedade globalizada" (Souza, 2009, p. 134).

Embora a sala de aula moderna seja caracterizada por elementos tecnológicos, Souza (2009) enfatiza a importância do encontro entre os integrantes do processo de ensino-aprendizagem. Por mais que se tenham à disposição modernos recursos tecnológicos, será no relacionamento, na proximidade entre professor e estudantes e nas emoções ali envolvidas que a aprendizagem se efetiva e ganha sentido e significado, tanto para o professor, quanto para o estudante.

A importância de estarem próximos fica evidente na fala dos professores pesquisados. Sobre o ser professor, os docentes afirmam que "ser professor é ser generoso" (Professora Cátia); "ser professor é respeitar o aluno, pois ele é muito importante" (Professora Ana); "Professor é aquele que te conduz, te orienta" (Professora Maria). Essas colocações apontam para características de generosidade, respeito e orientação sendo que os próprios professores destacam-nas como essenciais ao trabalho docente.

Os estudantes participantes da pesquisa dizem que o professor "tem que ser um tutor" (Júlia); "tem que direcionar, precisa ter um respeito pelo aluno" (Carla); "para ser professora tem que ter experiência externa e ter consciência de que ele está ali para ensinar o aluno" (Fernanda). A expres- 
são dos estudantes faz referência não somente às questões afetivas, mas também às questões técnicas necessárias para que o professor exerça a função docente.

Jusevicius (2006) enfatiza que:

Nota-se nas expressões dos alunos que a qualidade do relacionamento com o professor é um elemento importante na representação do que significa ser um bom professor, e esse aspecto sem dúvida pode ser um elemento que favorece o desenvolvimento de sentidos subjetivos facilitadores do envolvimento emocional do aluno em sala de aula (p. 74).

O complemento de frases, respondido pelos estudantes, apontou mais características positivas do que negativas nas afirmações à frase "a principal característica dos professores do curso é...". Dentre as características citadas, podem ser destacadas as seguintes: ética, determinação, competência, inteligência, dinamismo, criatividade, flexibilidade e conhecimento.

Em comparação com outros dados coletados, percebe-se que essas características oscilam entre o que de fato é característica existente e o que os estudantes desejam com relação aos seus professores. No grupo de discussão, foi possível identificar o desejo de que o professor do ensino superior tivesse um perfil idealizado de pessoa e de profissional. A ele caberia a condução das aulas, o bom relacionamento com os estudantes, ser amigo e ser exigente, ouvinte, disponível e resolver todos os problemas da turma, incluindo os pessoais.

Fica evidente a importância dos professores no processo de formação. Uma importância que vai além da função profissional, principalmente quando os estudantes afirmam, assim como Júlia, que "eles mantinham a hierarquia de professores, mas ao mesmo tempo se você tivesse algum problema, eles te ajudavam, todos sabiam que podiam ir lá e conversar".

Há a compreensão do papel do professor em sala de aula, mas também o desejo de que este Ihes seja mais próximo, acessível e participativo. O professor passaria a estar mais próximo dos estudantes e haveria uma interação maior e um aprendizado recíproco.

Tanto estudantes quanto professores expressam o significado dado à função de docente no ensino superior. $\mathrm{Na}$ sua linguagem estão implicados os sentidos dados às experiências anteriores, vivenciadas com outros docentes. A forma como os estudantes descrevem seus professores é permeada de emocionalidade.

\section{O estudante do Ensino Superior}

Os sentidos subjetivos são constituídos no processo de formação do sujeito e, permanentemente sofrem alterações, influenciam na constituição de novos sentidos, são organizados pelo pensamento, externalizados pela linguagem e integram a constituição da subjetividade do indivíduo. Junto com os processos simbólicos estão presentes as experiências pessoais, decorrentes do meio social, das inter-relações, dos códigos e significados de determinando gru- po, dos ambientes institucionalizados, enfim, nos espaços onde o indivíduo vivencia novas experiências (Jusevicius, 2006; González Rey, 2005b).

Os resultados da pesquisa, tanto com professores quanto com estudantes, apontaram características importantes para a compreensão dos sentidos subjetivos dos estudantes do Ensino Superior. O complemento de frases, por exemplo, apontou aspectos relacionados à persistência, à responsabilidade, à união e à determinação, qualidades apontadas como representativas daqueles estudantes. Analisadas juntamente com a forma como foram relatadas várias situações do curso durante a realização do grupo de discussão, ficou claro que os aspectos citados são expressões das experiências vivenciadas e das dificuldades superadas por todos ao longo do curso.

No grupo de discussão, Júlia afirma que ser estudante significa que "a gente tem que ser bem aberta para conseguir filtrar da melhor maneira o que o professor está passando, tem que ter maturidade para aceitar as críticas, tem que respeitar".

Pode ser percebido na colocação de Júlia que, além das características listadas no complemento de frases, a maturidade dos estudantes também é vista como um aspecto importante no Ensino Superior.

Outro dado importante é sobre a agilidade dos estudantes. Este fato é corroborado pela professora Cátia quando diz que os estudantes "estão com o notebook em sala de aula; você fala sobre um determinado assunto e eles na hora já estão pesquisando". Essa velocidade e quantidade de informação disponível exigem dos discentes o desenvolvimento das habilidades de discriminação, de seleção e de análise para que as facilidades de acesso aos conteúdos não acabe por prejudicar a construção do conhecimento, tanto por parte dos estudantes quanto dos professores.

Nessa mesma linha de reflexão, a estudante Carla enfatiza que ela "está aqui para aprender, para querer buscar mais e é difícil alinhar as ideias do professor com as suas ideias". O pensamento de Carla reflete aspectos relacionados à persistência e determinação, necessários para compreender e ser compreendido no âmbito de suas ideias e perspectivas de formação.

Essas afirmações, embora tragam significações muito particulares de cada estudante e de quais sentidos são atribuídos por eles, apontam, também, para situações que permeiam a relação entre professor e estudante, tais como as mencionadas acima pelos participantes da pesquisa. Assim, compreende-se que professores e estudantes, integrantes do processo educativo, cumprem um caminho de formação mútua de constituição de identidades, não só no aspecto individual, mas também de atuação profissional.

Como bem enfatiza Souza (2004, p. 44), pode-se "[...] atribuir sentido a determinado conhecimento ao se relacionar o conhecimento estudado com as experiências vividas". Quando o estudante não compreende as razões do estudo de determinados conteúdos, ele terá muito mais dificuldade de entender o significado do que é está sendo trabalhado e de atribuir-lhe sentido. 
Nesse sentido, Marinho-Araujo (2009, p. 158) lembra que o processo de ensino-aprendizagem "cumpre a função [...] de colocar-se como instrumento de organização, reorganização e ressignificação de valores e conceitos". Essa função tem reflexo direto sobre o estudante e sua atuação como profissional perante o meio social, de forma consciente e intencional e, ao mesmo tempo, de forma dialética, pois ele passa a ser, de acordo com a supracitada autora (2009, p. 159) "[...] corresponsável pelas transformações de seu contexto cultural", ao mesmo tempo em que essas influenciam o seu crescimento pessoal e profissional.

As experiências do estudante no Ensino Superior proporcionam uma formação não só teórica e metodológica, mas, fundamentalmente, a constituição de sentidos subjetivos relativos à sua profissão, ao seu campo de trabalho, ao conhecimento e a si próprio.

\section{O trabalho docente e a constituição de sentidos subjetivos}

O olhar mais atento sobre o trabalho docente no Ensino Superior indica que o vínculo, a compreensão e o respeito são aspectos percebidos como imprescindíveis. Sobre esse ponto, é possível citar tanto professores quanto estudantes quando fazem referência ao mesmo professor universitário que lecionou na primeira série do curso. A estudante Joana salienta que dentre as lembranças mais significativas estão as aulas do professor Antônio.

Eu acho que a relação que ele mantinha com os alunos, para o meu modo de vida, pela visão que eu tinha do curso, era mais o desafio que ele propunha; todos os trabalhos eram de interpretação profunda, que você tinha que realmente olhar além. (Estudante Joana)

A professora Cátia também apresenta o mesmo professor como um referencial importante na sua formação acadêmica, profissional e de docência. Ela lembra que "o professor Antônio tinha um humor muito inteligente, que fazia você ficar acesa, ficar ligada no que ele estava falando; sempre tinha alguma coisa por trás".

O fato de o mesmo professor ser citado tanto por estudantes quanto pela professora do curso demonstra a importância dele para a constituição da subjetividade desses sujeitos. Foi verificado junto à coordenação que esse docente leciona nas primeiras séries do curso, tem uma experiência de mais de 10 anos na docência, atua no mercado profissional da área de formação e apresenta características de respeito, simplicidade, comprometimento e interação com os estudantes.

Sobre o relacionamento professor-aluno durante o curso, a maioria dos estudantes afirmou que foi bom. $O$ mesmo grupo, tanto no complemento de frases quanto no grupo de discussão, de forma anônima, apresenta aspectos relacionados às questões comportamentais, seguidos por aspectos ligados à questão profissional e, por último, aspectos acadêmicos.
Dentre os aspectos comportamentais, os estudantes citaram que aprenderam com os professores que: "preciso me preparar para lidar com pessoas", "tenho sempre que melhorar", "devemos sempre fazer bem feito", "devemos aprender a conviver com as diferenças", "as diferenças devem ser respeitadas" e "nunca desistir". Na perspectiva de Tacca (citado por Jusevicius, 2006), fica claro pelas afirmações acima que estudantes e docentes "[...] além de compartilharem um espaço físico, compartilham-se como pessoas, ou seja, interagem como sujeitos, constituindo-se mutuamente em sua subjetividade" (p. 30).

O professor compartilha com os estudantes as suas experiências e relata o mais significativo de cada situação. Os estudantes, por sua vez, recebem a informação, buscam a compreensão com base em suas experiências, atribuem à narrativa um sentido e, de forma particular, atribuem sentidos ao relato.

Sobre os aspectos profissionais, os estudantes afirmam que aprenderam que "ser bom aluno significa ser bom profissional", "devemos respeitar e trocar ideias", "temos prazos a cumprir" e "responsabilidade". Esses foram aprendizados elaborados a partir das atividades educativas, mas que estão diretamente relacionados à atuação profissional. Nota-se que as afirmações acima não são conteúdo de disciplinas do currículo acadêmico, mas constituídas nas trocas existentes no ambiente educacional no período de realização do curso no Ensino Superior. Constituição que ocorre por meio da interação, do relacionamento e do convívio entre estudantes e professores, tanto na sala de aula, quanto em laboratórios ou em visitas técnicas.

Quanto ao aprendizado relacionado aos aspectos acadêmicos para a construção do conhecimento, os estudantes citam que é relevante: "ler bastante", "é importante diversificar o conhecimento", "não se aprende só na universidade" e "posso aprender muito mais do que penso". Também nas questões ligadas mais diretamente ao aprendizado universitário, os relatos estão vinculados aos aspectos subjetivos da formação.

O que fica como mensagem para os estudantes são sentidos particulares sobre o que é aprender. São sentidos subjetivos atribuídos pelos estudantes ao seu processo de formação universitária, que não estão nos livros, mas são constituídos por meio do relacionamento com os seus professores e com seus colegas. Para Jusevicius "[...] o ensino não é uma atividade despersonalizada, e os processos de sentido subjetivo que aparecem em relação à aprendizagem, tem muito a ver com a qualidade da comunicação e com o clima da sala de aula" (2006, p. 76).

Fica evidente nas afirmações dos estudantes que o aprendizado no ensino superior está além do conteúdo acadêmico previsto na matriz curricular do curso. As narrativas levam a uma reflexão sobre a importância da troca de experiências entre professores e estudantes e a forte influência que estas têm sobre a formação do futuro profissional e sobre o trabalho docente no Ensino Superior.

Sobre o que de mais significativo foi aprendido com os professores do ensino superior, as respostas foram rela- 
cionadas a aspectos como conhecimento, valores pessoais, motivação, profissionalismo e autoavaliação. Algumas afirmações do complemento de frases podem ser dadas como exemplo: "o conhecimento obtido nas matérias", "tolerância, persistência, dedicação, superação", "que o conhecimento é algo que ninguém tira e isso nós levamos para o resto da vida" e "determinação e coragem".

Quanto às características em comum dos bons professores, tanto docentes quanto estudantes citam o compromisso com o ensino, o comprometimento com o conteúdo e com os estudantes, o gosto pela profissão, a generosidade na hora de explicar e estar disponível para atender aos estudantes. A professora Cátia afirma que "uma questão fundamental é o conhecimento, ter o domínio do que está falando e passar aquilo de maneira interessante" e complementa afirmando que o importante "é o respeito que ele passa para os alunos; respeitar que o aluno está aprendendo".

A professora Cátia enfatiza, também, que "o professor não tem o conhecimento pronto; ele leva até onde ele pesquisou e aí, conforme o interesse vai acontecendo, os alunos também complementam e as coisas vão acontecendo".

$\mathrm{Na}$ visão dos docentes, os estudantes também contribuem para a aprendizagem, tanto acadêmica quanto profissional. A professora Maria afirma que "estou sempre me renovando, estou sempre aprendendo com eles. Eu sinto o retorno deles". Quando se refere aos seus professores formadores, Maria afirma que "ela [sobre a sua professora formadora] tem total confiança em mim; é aquela professora eterna; ela diz que hoje é minha amiga". Essa reciprocidade de sentimentos e compreensão da presença do professor e do estudante no processo de aprendizagem e de troca constante é extremamente importante para que o conhecimento seja construído e que os sujeitos do processo atribuam sentidos às atividades que integram o processo de ensino-aprendizagem.

Dentre as ferramentas facilitadoras da construção do conhecimento, pode-se constatar, pelas respostas do complemento de frases, que os estudantes valorizam muito as experiências extraclasses. Para complementar a frase "as experiências mais significativas vivenciadas com meus professores foram..." os estudantes afirmaram: "pesquisas fora de sala de aula", "visitas que fizemos a empresas", "desfiles, exposições, trabalhos criativos", "eventos fora da sala de aula".

A importância da relação entre professores e estudantes pode ser constatada, também, nas afirmações: "o incentivo que alguns deram", "dividir conhecimentos", a "relação de amizade" e "conversas e troca de experiências". As visitas técnicas também são citadas pela professora Cátia "gosto muito de visita técnica para poder vivenciar aquilo que foi estudado".

Como base nos relatos de professores e estudantes percebe-se que as experiências envolvidas no processo educativo e, consequentemente, constitutivo da subjetividade de professores e alunos, estão relacionadas não somente ao ambiente formal de sala de aula. Outros meios e ambientes estão incluídos nesse processo. Laboratórios, orientações individuais, tarefas individuais e em grupo, troca de e-mails, conversas em ambientes informais, dentre outros eventos influenciam na subjetividade e na constituição dos sentidos subjetivos.

\section{Considerações}

A constituição dos sentidos subjetivos é única, particular, individual, mas não é uma ação isolada do sujeito. É permeada por processos simbólicos, por emoções, pelos discursos sociais, pelos valores, pelas representações, pela cultura e pela história de cada indivíduo. Conhecer os sentidos subjetivos imbricados no processo de ensino e de aprendizagem no Ensino Superior significou compreender o "como" se fala e não somente "o que" é relatado. São as emoções e as simbologias presentes nas narrativas que possibilitaram o contato com os sentidos subjetivos.

Os resultados da pesquisa confirmam a influência do trabalho docente sobre a constituição de sentidos subjetivos de estudantes do Ensino Superior. Nesse caso, destacam-se indicadores que favorecem a constituição de sentidos subjetivos que permeiam a qualidade do relacionamento entre professores e alunos, tais como generosidade, respeito, ética, inteligência, flexibilidade, conhecimento, criatividade, dentre outros.

O processo educativo é constituído por momentos de troca e de crescimento pessoal e profissional. Essa relação dialética entre estudantes e professores tem como pano de fundo o contexto sócio-histórico-cultural e as características individuais de cada um deles. $E$ quando se faz referência à relação dialética, afirma-se que, pelos resultados da pesquisa, o docente também é influenciado pelos estudantes na constituição dos sentidos subjetivos no ambiente educativo, no contexto da sala de aula e no cotidiano da universidade. Outro aspecto importante é a dialética presente na questão profissional, em que o professor participa da formação dos estudantes e estes mobilizam os professores na busca do crescimento e do aperfeiçoamento da profissão docente.

O aprendizado e o desenvolvimento do estudante no decorrer do processo educativo não acontecem pela simples presença de professor e de estudantes no mesmo ambiente físico. É preciso que exista interação entre ambos, que haja troca de experiências e respeito às diferenças e, principalmente, que seja estabelecido um vínculo entre os sujeitos da educação. Esse vínculo precisa ser fortalecido e consolidado em todos os encontros, e ser marcado pelo incentivo e pela motivação dos professores. Essas atitudes não estão vinculadas a nenhum conhecimento teórico. São valores subjetivos envoltos em emoções, relacionamentos, desejos e histórias de vida de cada indivíduo.

Os resultados encontrados corroboram com outros autores (Souza, 2004; Placco, 2004) sobre a importância do bom relacionamento entre professores e estudantes. Relacionamento que não está somente nos eventos sociais, mas nas atitudes de aproximação e de interesse do professor com os aspectos individuais e singulares dos estudantes e a vinculação entre eles. A disposição do professor em ajudar foi apontada como uma das principais características 
do bom professor e um dos pontos mais marcantes da vida acadêmica.

Cabe aqui registrar que os resultados da presente pesquisa possibilitam uma compreensão mais sistematizada da constituição de sentidos subjetivos no processo de ensino e aprendizagem no Ensino Superior, e também apontam a necessidade de um trabalho de pesquisa mais amplo, integrando de forma mais aprofundada as narrativas de estudantes e de professores. Outros estudos sobre essa temática podem ser realizados como, por exemplo, a utilização dos procedimentos metodológicos de investigação, em forma de estudo longitudinal, viabilizando a compreensão de como os sentidos subjetivos são constituídos ao longo do curso de graduação e quais aspectos do trabalho docente estariam mais fortemente envolvidos nesse processo.

\section{Referências}

Bariani, I. C. D., Buin, E., Barroz, R. C., \& Escher, C. A.(2004). Psicologia escolar e educacional no ensino superior: análise da produção científica. Psicologia Escolar e Educacional, 8(1), 17-27.

Brasil. Ministério da Saúde. Conselho Nacional de Saúde. Conselho Nacional de Saúde [CNS] (1996). Resolução nº 196, de 10 de outubro de 1996. Dispõe sobre diretrizes e normas regulamentadoras de pesquisas envolvendo seres humanos. Brasília-DF: CNS.

Broilo, C. L., Fagundes, M. C. V., Gomes, M. Q., Jardim, I. R., \& Braccini, M. L.(2010). A formação no território do trabalho: a construção da profissionalidade dos docentes universitários. Em M. I. Cunha (Org.), Trajetórias e lugares de formação da docência universitária: da perspectiva individual ao espaço institucional (pp. 83-104). São Paulo: Junqueira, \& Marin.

González Rey, F. L. (2005a). Pesquisa qualitativa em psicologia: caminhos e desafios. São Paulo: Pioneira.

González Rey, F. L. (2005b). Sujeito e subjetividade: uma aproximação histórico-cultural. São Paulo: Pioneira.

González Rey, F. L. (2007). As categorias de sentido, sentido pessoal e sentido subjetivo: sua evolução e diferenciação na teoria histórico-cultural. Psicologia da Educação, (24), 155-179.

Jusevicius, V. C. C. (2006). Subjetividade em sala de aula: a relação professor-aluno no ensino superior. Tese de Doutorado, Pontifícia Universidade Católica, Campinas - SP. Disponível:http:// www.bibliotecadigital.puc-campinas.edu.br/tde_busca/arquivo. php?codArquivo $=10$

Lüdke, M., \& André, M. E. D. A. (1986) Pesquisa em Educação: abordagens qualitativas. São Paulo: EPU.

Marinho-Araújo, C. M. (2009). Psicologia escolar na educação superior: novos cenários de intervenção e pesquisa. Em C. M. Marinho-Araújo (Org.), Psicologia Escolar: novos cenários e contextos de pesquisa, formação e prática (pp. 155-202). Campinas (SP): Alínea.

Meira, M. E. M., \& Antunes, M. A. M. (2003). Em M. E. M. Meira, \& M. A. M. Antunes (Org.), Psicologia Escolar: práticas críticas (p. 7). São Paulo: Casa do Psicólogo.

Placco, V. M. N. S. (2004). Relações interpessoais em sala de aula e desenvolvimento pessoal de aluno e professor. Em L. R. Almeida,\& V. M. N. S. Placco (Org.), As relações interpessoais na formação de professores (pp. 7-19). São Paulo: Loyola.

Santos, S. C. (2001). O processo de ensino-aprendizagem e a relação professor-aluno: aplicações dos sete princípios para a boa prática na educação de ensino superior. Cadernos de Pesquisas em Administração, 8(01), 69-82.

Serpa, M. N. F., \& Santos, A. A. A. dos. (2001). Atuação no ensino superior: um novo campo para o psicólogo escolar. Psicologia Escolar e Educacional, 5(1), 27-35.

Souza, K. S. M. (2009). O sujeito da educação superior: subjetividade e cultura. Psicologia em Estudo, 14(1), 129-135.

Souza, V. L. T. (2004). Relações interpessoais e universidade: desafios e perspectivas. Em L. R. Almeida, \& V. M. N. S. Placo (Orgs.), As relações interpessoais na formação de professores (pp. 35-492). São Paulo: Loyola.

Stangherlim, R. (2007). Sentidos subjetivos identitários da prática profissional de formadores do PROVE. Tese de Doutorado, Pontifícia Universidade Católica, São Paulo-SP. Recuperado: http://www.sapientia.pucsp.br//tde_busca/arquivo. php?codArquivo $=3789$

Tacca, M. C. V. R., \& González Rey, F.L. (2008). Produção de sentido subjetivo: as singularidades dos alunos no processo de aprender. Psicologia Ciência e Profissão, 28(01), 138-161. 


\section{Sobre as autoras}

Silvia Simão de Matos (smattos@univille.br)

Graduada em Psicologia pela Universidade da Região de Joinville e em Comunicação Social com Habilitação em Relações Públicas pela PUCRS. Pós-Graduada em Comunicação e Economia Política pela PUCRS e em Engenharia de Produção pela UFSC (2002). Professora dos Cursos de Administração e de Gastronomia da Universidade da Região de Joinville (Univille).

Márcia de Souza Hobold (marcia.hobold@univille.br)

Doutora em Educação pela Pontifícia Universidade Católica de São Paulo (PUC-SP), professora do Departamento de Psicologia da Universidade da Região de Joinville (Univille) 
